\title{
Estudo Prospectivo Relativo ao Uso do Fruto Coco como Matéria-prima para Fabricação de Cosméticos
}

\author{
Prospective Study About the Use of coconut fruit as as Raw Material for \\ the Manufacture of Cosmetics
}

\author{
Isabella Sampaio ${ }^{1}$ \\ Solange Ferreira ${ }^{1}$ \\ Paulo Juiz ${ }^{1}$ \\ ${ }^{1}$ Universidade Federal da Bahia, Salvador, BA, Brasil
}

\begin{abstract}
Resumo
O coco é considerado um fruto de grande importância socioeconômica, com multifuncionalidade, pois é fonte de matéria-prima para diversos ramos industriais, como agroindústrias, têxteis, cosméticos e farmacêuticos. Apesar do potencial aproveitamento do fruto como um todo, seu uso está mais concentrado na área alimentícia. Assim, este estudo teve como objetivo realizar um levantamento de informações sobre patentes relacionadas ao uso do coco como matéria-prima para fabricação de cosméticos. Utilizando o software de busca de patentes Orbit Intelligence, percebeuse que países asiáticos lideram o ranking de investimentos nessa área e que apesar de o Brasil ser considerado um grande produtor de coco, e também possuir uma área geográfica adequada, ainda precisa de grandes investimentos para implementar produção direcionada à área de cosméticos.
\end{abstract}

Palavras-chave: Coco. Prospecção. Cosméticos.

\begin{abstract}
The coconut is considered a fruit of great socioeconomic importance, with multifunctionality as it is a source of raw material for various industrial sectors such as agroindustries, textiles, cosmetics and pharmaceuticals. Although it has the potential of total utilization of the fruit, its uses are still related to the alimentary area. Thus, this study aims to carry out a survey of patent information related to coconut in its use as raw material for the manufacture of cosmetics. Using the Orbit Intelligence patent search base, it was noticed that Asian countries lead the ranking of investments in this area and that although Brazil is considered a major coconut producer and also has a suitable geographic area, it still needs large investments to implement production directed to the area of cosmetics.
\end{abstract}

Keywords: Coconut. Cosmetics. Prospection.

Área Tecnológica: Biotecnologia. Propriedade intelectual. 


\section{Introdução}

O coqueiro é uma das plantas frutíferas mais difundidas de maneira natural por todo o mundo. Oriunda do Sudeste Asiático, a planta foi introduzida no Brasil pelos portugueses, por volta do ano de 1553. O coco é cultivado em cerca de 90 países que destinam o fruto, principalmente, para a produção de copra e óleo, principais derivados do coco comercializados no mercado internacional. De acordo com estudos realizados pelo Banco do Nordeste, em publicação de Brainer (2017), atualmente, a área mundial colhida de coco é cerca de 12 milhões de hectares, produzindo aproximadamente setenta milhões de toneladas (BRAINER, 2017). Segundo esse autor, o maior produtor mundial de coco é a Indonésia, seguido pelas Filipinas e depois Índia que juntos são responsáveis por $72,5 \%$ da produção mundial. O Brasil participa de $15,3 \%$ da produção, conferindo-lhe a quarta colocação no ranking dos maiores produtores mundiais de coco.

A Organização das Nações Unidas para a Alimentação e Agricultura (FAO) aponta que a produtividade de cocos na Ásia (que é responsável por quase $90 \%$ da produção mundial) está caindo, visto que a maior parte dos coqueirais foram plantados há 50 anos, enquanto o ápice da produtividade dessas plantas é entre os 10 e os 30 anos. Já o Brasil tem grande potencial para aumentar a produção e as exportações desse produto, pois a grande maioria dos coqueirais que são localizados nas terras brasileiras são jovens, e ainda há extensão territorial para expandir a produção (BRAINER, 2017).

O potencial de aproveitamento do fruto coco é de $100 \%$ e interessa a diversas áreas, desde a questão energética, aplicáveis à obtenção do biodiesel do coco (TOMMASI et al., 2014), perpassando pela utilização da fibra do coco como reforço em compósitos com plástico viável para minimização do impacto ambiental e social (COSTA, 2018), e chegando a um dos seus usos mais proeminentes que é a área alimentícia.

Segundo Fabian Laszlo, criador da empresa Laszlo de cosméticos e produtos de aromaterapia, o coco possui propriedade altamente hidratante e esse fator propicia o desenvolvimento de produtos cosméticos para o cuidado com a pele, especialmente pela alta concentração de ácido láurico, um tipo de ácido graxo com propriedades antissépticas, eficientes no combate de micro-organismos que causam doenças de pele. Além disso, a polpa é tradicionalmente conhecida por suas propriedades hidratantes e umectantes.

Do coco é extraído um óleo que é comumente utilizado para a produção de sabonetes, cremes, sabões, velas, margarinas, entre outros, usados em sua maioria pelas indústrias alimentícias e cosméticas. Porém estudos da Organização Mundial de Saúde (OMS) apontam que o extrato biológico advindo do coco é benéfico para o tratamento de feridas e queimaduras, suscitando o seu poder cicatrizante e anti-inflamatório (FARMACÊUTICAS, 2017).

Pesquisa realizada com componentes químicos do óleo de coco, como o ácido láurico e o cáprico, correlacionou o potencial biológico desse óleo com propriedades antivirais, antimicrobianas e antioxidantes ao ser capaz de promover a normalização de lipídios corporais, protegendo o fígado contra os efeitos hepatotóxicos do álcool, além de melhorar a resposta do sistema imunitário, promovendo uma cicatrização de feridas (FARMACÊUTICAS, 2017). O óleo apresenta em sua composição vitamina E e ômega 3, ácido graxo, que ajuda a diminuir o colesterol ruim. 
O óleo de coco também é considerado um dos óleos de beleza mais nobres e, por ser natural, ainda tem a vantagem de não conter aditivos químicos indesejados como a maioria dos cosméticos convencionais. Não existem números que deem a real dimensão do mercado de cosméticos naturais, orgânicos, veganos e sustentáveis no Brasil, mas alguns estudos reforçam que esse mercado, apesar de ainda pouco expressivo, tem um potencial de crescimento surpreendente. Segundo relatório da Grand View Research, o mercado global orgânico de cuidados pessoais deverá atingir US\$25,11 bilhões até 2025 (REVISTA COMESTIC INNOVATION, 2018).

O Brasil era o terceiro país do ranking do consumo mundial de beleza e higiene, mas caiu para a quarta posição em razão da crise econômica, ficando atrás dos EUA, China e do Japão. Mas o setor avança, apesar da queda no ranking mundial, a indústria de higiene e beleza brasileira cresceu mais que a economia do País nos últimos anos. Em 2017, o setor registrou um faturamento de 102 milhões de reais em 2017, uma alta de 3,2\% em relação a 2016 (99 milhões de reais). Para 2018, a expectativa é de um aumento de 3,8\%, atingindo uma receita 106 milhões de reais. No ano passado, o PIB brasileiro cresceu apenas 1\% (REVISTA VEJA, 2018).

Dessa forma, o objetivo deste trabalho foi realizar um estudo prospectivo em bancos de patentes sobre o uso do fruto coco para o desenvolvimento de cosméticos, avaliando como o Brasil, um grande produtor dessa matéria-prima e com potencial para expansão, está inserido nesse mercado.

\section{Metodologia}

Trata-se de uma pesquisa prospectiva e exploratória realizada a partir de busca de documentos de patentes no sistema Orbit Intelligence, que dá acesso à base de dados proprietária da FAMPAT, cobrindo publicações de patentes, em todos os segmentos tecnológicos.

A pesquisa utilizou como palavras-chave, nos campos de busca título e resumo, os termos: coconut + , cosmetic + , skin + , associadas entre si por meio do conector booleano AND. O escopo da prospecção é apresentado na Tabela 1. Para refinamento da pesquisa foram analisados documentos de patentes segundo a classificação de patentes IPC (International Patent Classification) e CPC (Cooperative Patent Classification), nas áreas de abrangências A61K e A61Q, que se referem respectivamente a preparações para finalidades médicas, odontológicas ou higiênicas e uso específico de cosméticos ou preparações similares para higiene pessoal.

A primeira estratégia de busca teve como objetivo mapear as patentes que utilizam o fruto coco como matéria-prima na fabricação de cosméticos, identificando os principais países depositantes e tecnologias relacionadas nesse segmento nos últimos vinte anos. Posteriormente foi feito o recorte das patentes brasileiras para que fosse possível visualizar o panorama nacional que vem sendo explorado e nichos mercadológicos existentes no Brasil.

Os resultados obtidos foram analisados e discutidos com base no levantamento de bibliografia relacionada ao tema, como artigos científicos, reportagens, textos extraídos de livros e encontrados nos sites Pubmed, Google Acadêmico, Scielo, Lilacs. 
Tabela 1 - Escopo da pesquisa para busca de patentes relacionadas ao uso da fruta coco para fabricação de cosméticos

\begin{tabular}{cccc} 
& Palavras-chave & & Resultados \\
Coconut + & Cosmetic + & Skin + & 19509 \\
X & & & 428 \\
X & X & & 191 \\
X & X & X \\
\hline
\end{tabular}

Nota: As palauras-chave foram associadas por meio do conector booleano AND.

Fonte: Elaborada pelos autores deste artigo (2018)

\section{Resultados e Discussões}

Os resultados apontaram 191 depósitos de patentes relacionadas às palavras-chave coconut + AND cosmetic + AND skin + nos últimos vinte anos usadas no campo de busca título e resumo do sistema Orbit. A Figura 2 apresenta os principais países que produzem tecnologias relacionadas ao objetivo do estudo. A China configura o país detentor do maior número de família de patentes, 56 no total, seguido da Coréia, com 37 famílias, Japão com 32 e 17 patentes depositadas via Tratado de Cooperação de Patentes (PCT).

Em 2011, os Estados Unidos concentravam a maior parcela do consumo de produtos de beleza, atingindo $14.8 \%$ do total, contudo essa participação tem se retraído ao longo da última década e a China tem despontado em relação aos mercados tradicionais e consolidados (ABIHPEC, 2012).

Figura 1 - Países prioritários com depósitos de patentes relacionadas ao uso da fruta coco para fabricação de cosméticos

\section{Países Prioritários}

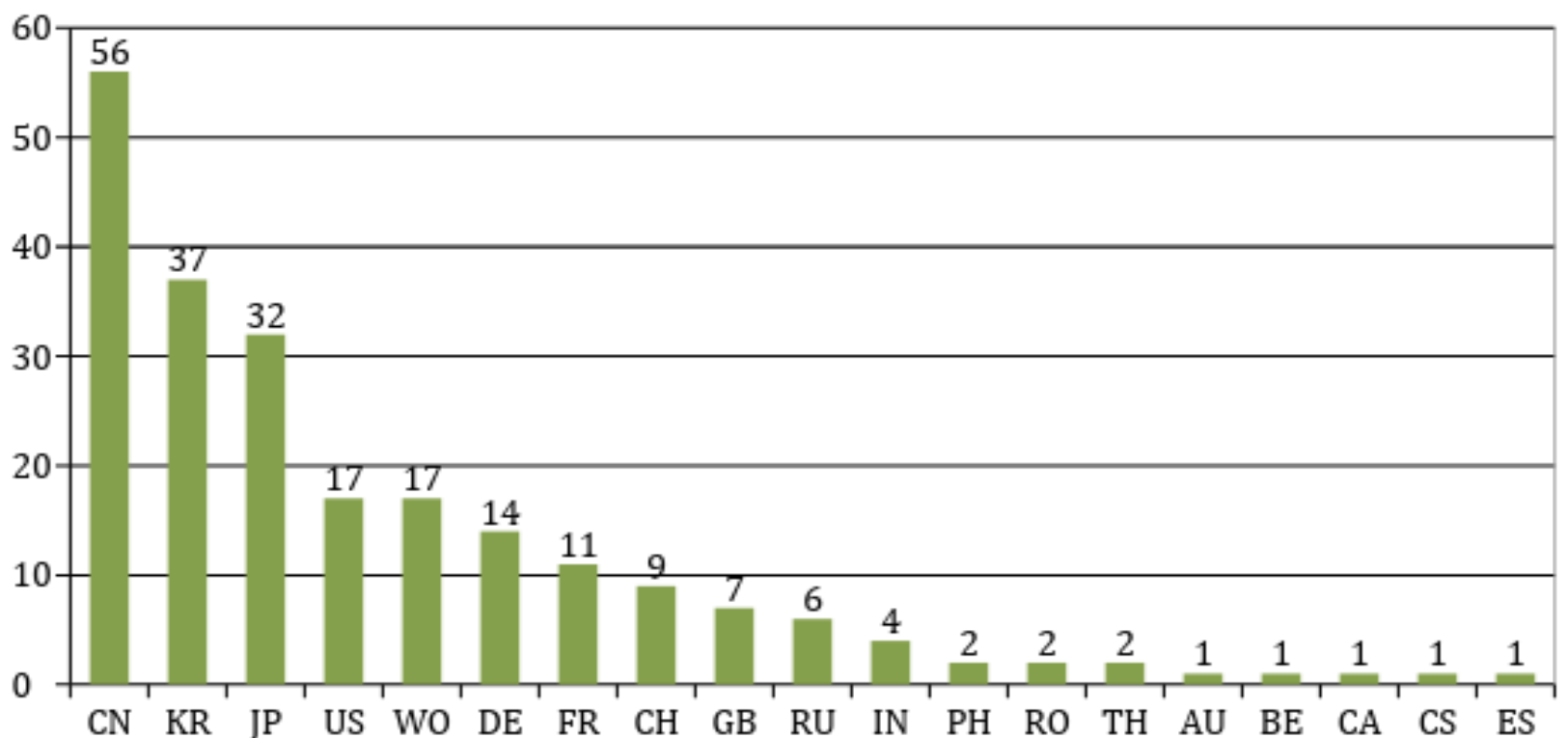

Fonte: Elaborada pelos autores deste artigo, a partir de dados coletados no Orbit (2018) 
A China avança mais rápido do que os demais países do $\mathrm{BRIC}^{1}$ tanto nos investimentos em ciência e tecnologia quanto no envolvimento do setor produtivo nos esforços de inovação, segundo estudo apresentado pelo Instituto de Pesquisa Econômica Aplicada (IPEA, 2015). Dados compilados pelo pesquisador Luiz Ricardo Cavalcante, da divisão de estudos setoriais do Ipea, mostram que os investimentos chineses em pesquisa e desenvolvimento tecnológico passaram de cerca de 0,8\% do Produto Interno Bruto (PIB) em 2000 para 1,44\% em 2008 e ainda, com desempenho crescente na última década (BID, 2017) com mais de $2 \%$ do PIB investido em pesquisa e desenvolvimento (P\&D).

No entanto, quando utilizamos a ferramenta do sistema Orbit conhecida como filtro NPN $>1$, utilizada para avaliar se uma mesma patente foi depositada em mais do que um país além do de prioridade unionista, percebemos (Figura 2) que a China não lidera mais o ranking, o que sugere, para China, um incentivo em pesquisa e desenvolvimento de produtos cosméticos, no entanto uma política fraca de proteção por meio do depósito de patentes em outros países. Com base nos resultados apresentados pela Figura 2, que apresenta a relação de países com mais de uma família de patentes relacionadas ao uso do coco para fabricação de cosméticos utilizando a ferramenta NPN>1, verificamos que o maior número de patentes foi depositado via PCT, composto de 152 países signatários, o que mostra uma preocupação dos inventores em ampliar o escopo de proteção geograficamente aumentando a competitividade do produto acabado e ampliando os nichos mercadológicos.

Figura 2 - Países prioritários com depósitos de patentes relacionadas ao uso da fruta coco para fabricação de cosméticos utilizando a ferramenta NPN >1

\section{QP NPN>1}

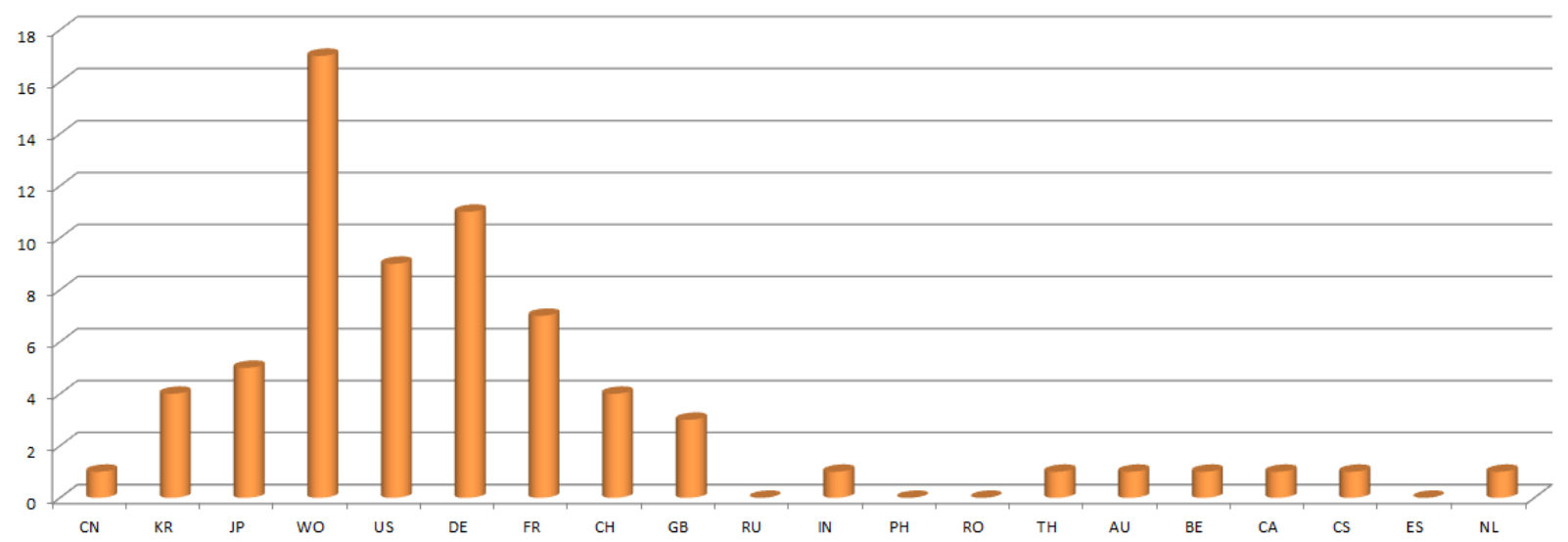

Nota: NPN - NUMBER OF PUBLICATIONS IN A FAMILY.

Fonte: Elaborada pelos autores deste artigo, a partir de dados coletados no Orbit (2018)

Dentre as principais empresas que utilizam o coco na fabricação de cosméticos, podemos destacar (Figura 3): Lion Corporation, empresa japonesa, fabricante de produtos de higiene e cuidados pessoais, LG Household, organização sul-coreana que gerencia os negócios de cosméticos, eletrodomésticos e bebidas, e Amore Pacific Corporation, holding também sul-coreana que também atua no ramo de cosméticos e estética operando mais de trinta empresas da área. 
Figura 3 - Empresas que depositaram patentes relacionadas à fabricação de cosméticos a base de coco

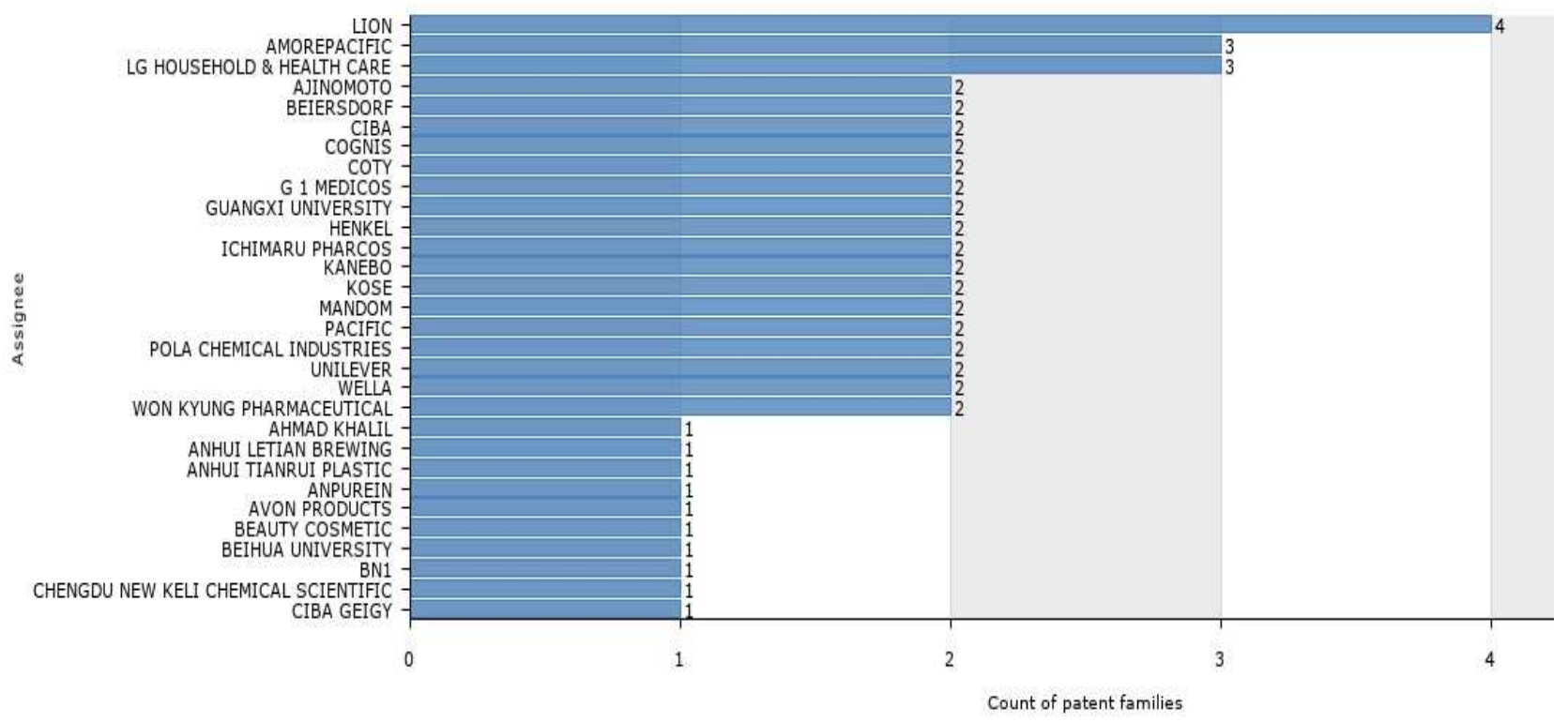

Fonte: Orbit (2018)

Com a estratégia de busca utilizada, o Brasil foi considerado o $14^{\circ}$ nicho mercadológico selecionado pelas empresas do ramo para depósito de patentes relacionadas ao uso do coco na indústria de cosméticos, com três famílias de patentes identificadas (Figura 4).

Figura 4 - Localização dos mercados e competidores relacionados a patentes sobre o uso do coco na fabricação de cosméticos

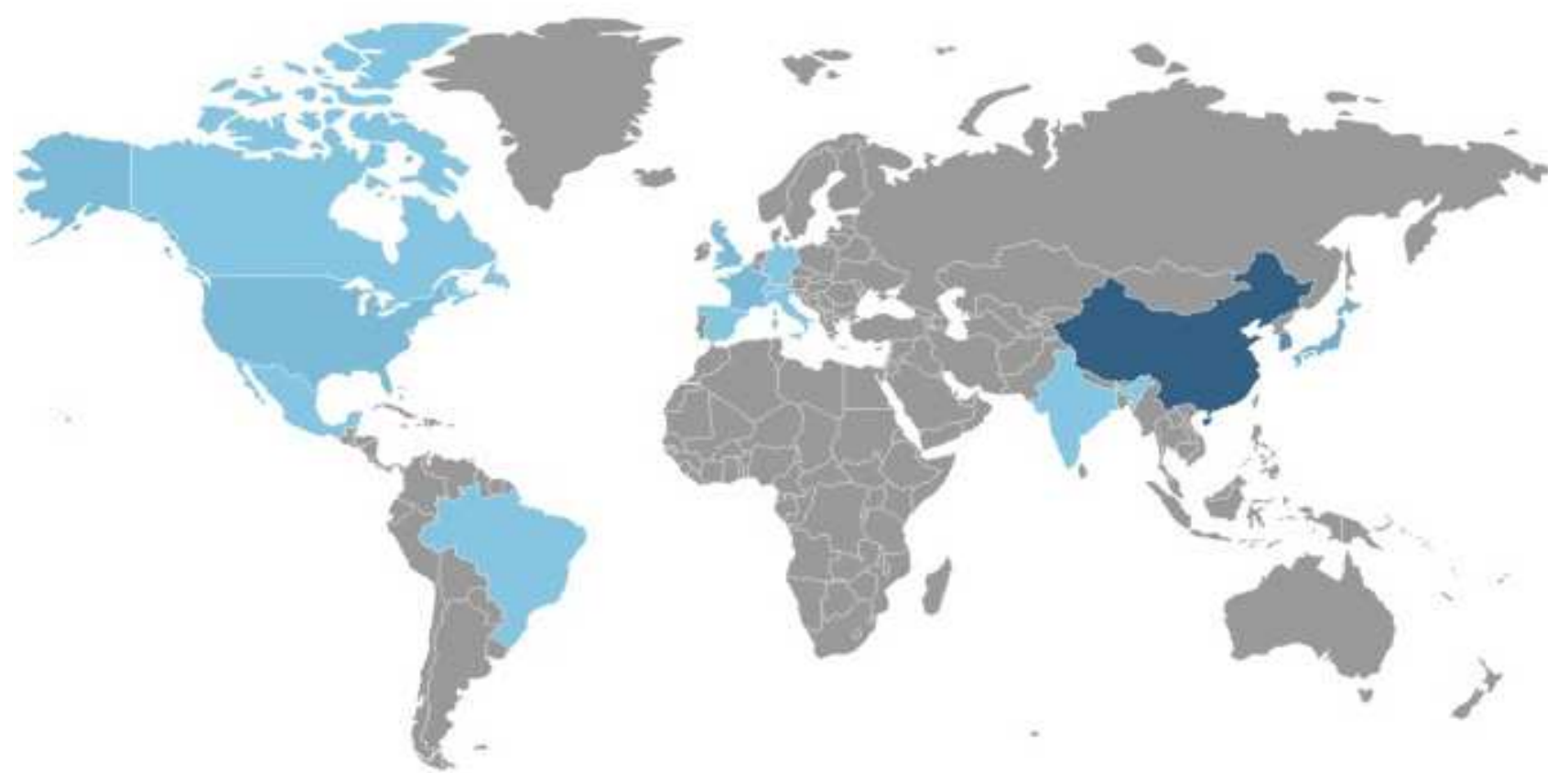

1

Fonte: Orbit (2018) 
Apesar de o Brasil figurar entre uma das maiores produtores de coco do mundo, sendo o maior fora do continente asiático (SEBRAE, 2016), tendo sido o quarto produtor de coco no ano de 2008, ficando atrás apenas de Indonésia, Filipinas e Índia (MARTINS, 2011), e ainda, é detentor de uma área geográfica com condições climáticas favoráveis para aumentar a produção do coco, entendemos que, no Brasil, o aproveitamento do coco com finalidade industrial está mais voltado para os processos extrativos da água para o consumo e não do fruto para fabricação de cosméticos. Essa observação abre uma discussão sobre as inúmeras possibilidades mercadológicas bem como a existência de um setor de pesquisa e inovação ainda pouco explorado e com grande potencial, de modo que políticas governamentais deveriam ser instituídas para estimular o desenvolvimento do setor tecnológico na indústria de cosméticos no País.

No final do século XX, a indústria dos cosméticos apresentou um grande crescimento por conta do perfil de consumidores cada vez mais exigentes com cuidados com a beleza e a saúde. Além disso, a inserção da nanotecnologia possibilitou a conquista de resultados inovadores nesta área, a partir de 1995 na França, já com o lançamento de um creme de combate ao envelhecimento com nanocápsulas de vitamina (NEVES, 2008).

Esse cenário de evolução é acompanhado também pelos depósitos de patentes relacionadas ao uso do coco na fabricação de cosméticos, principalmente a partir de 2014, como podemos verificar na Figura 5. Esse fato se dá pela visibilidade de novos produtos, tendências e tecnologias aliados às práticas de uso sustentável de recursos naturais, em que cosméticos fabricados de matéria-prima natural ganham importância no cenário mundial (ABIHPEC, 2014-2015). Vejamos que o crescimento de depósitos é marcante na última década e mostra o interesse pelas empresas no aproveitamento do coco para além da simples extração de água para consumo.

Figura 5 - Número de depósitos de famílias de patentes nos últimos vinte anos

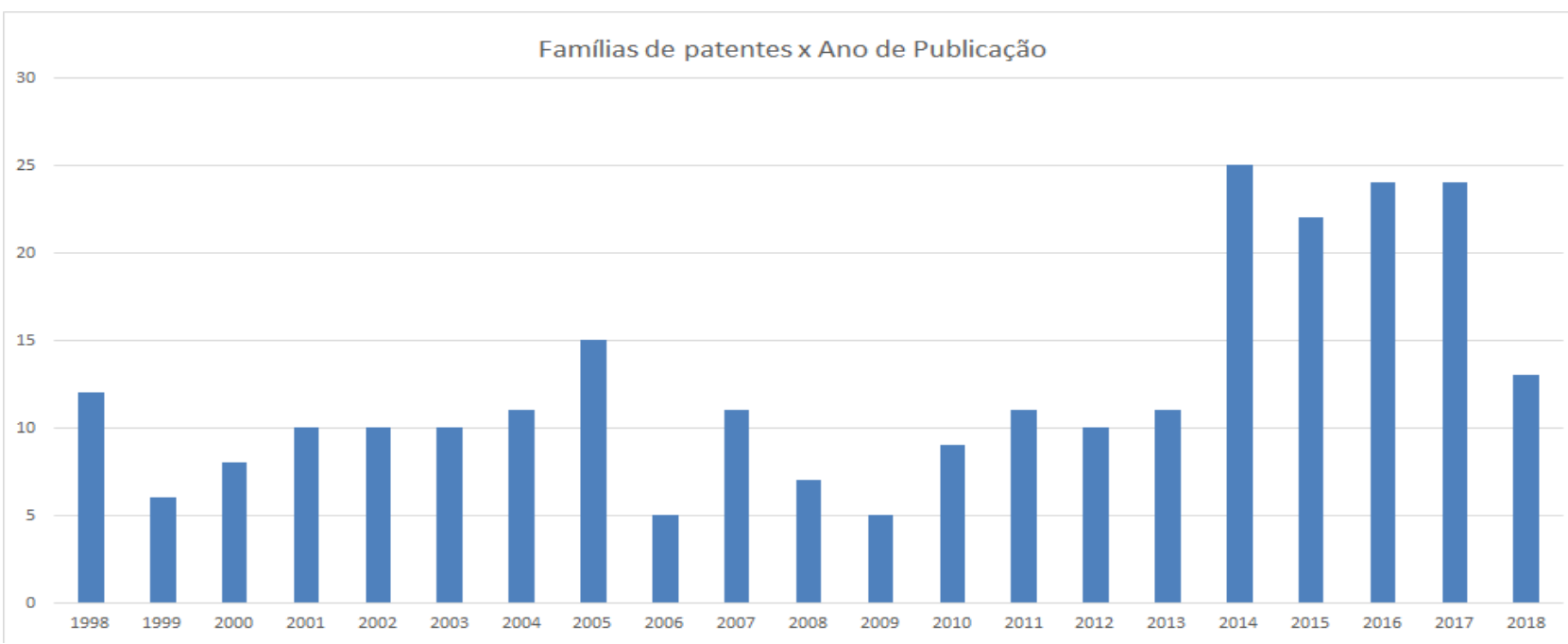

Fonte: Elaborada pelos autores deste artigo, a partir de dados coletados no Orbit (2018)

Cabe salientar que, em relação aos dados apresentados pela Figura 4, para o ano de 2018 a análise não foi considerada, tendo em vista o período de 18 meses de sigilo exigido pela legislação patentária.

A Figura 5 ilustra o status legal das patentes depositadas. Os resultados mostraram que $23,04 \%$ das patentes foram concedidas, $28,80 \%$, foram extintas, $13,61 \%$ expiradas, $11,52 \%$ 
revogadas e 23,04\% pendentes. Segundo a Lei n ${ }^{\circ}$ 9.279, de 14 de maio de 1996, uma patente será extinta quando:

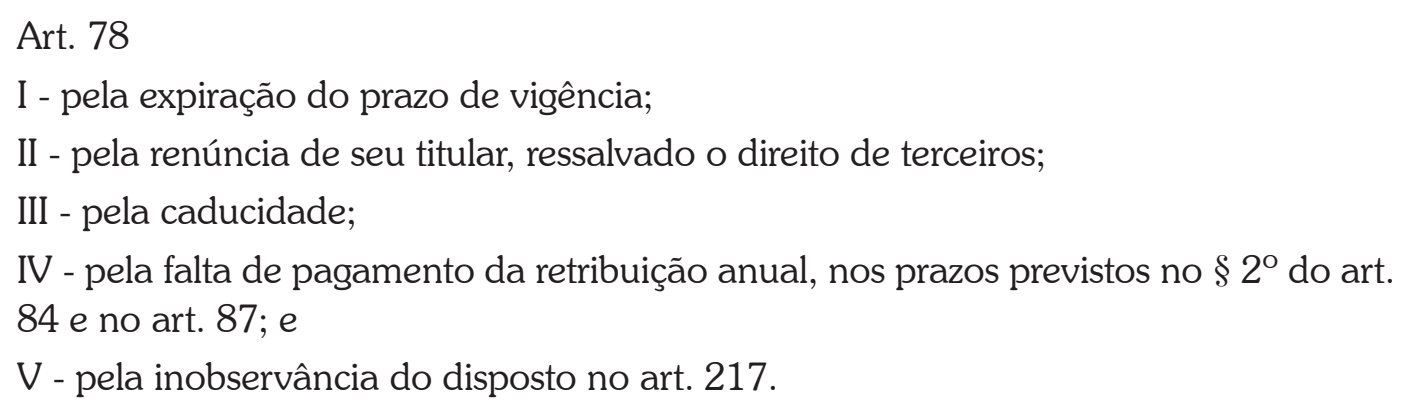

Mais de 50\% (patentes concedidas somadas àquelas com pedidos pendentes) das patentes têm potencial de serem licenciadas e $13,61 \%$ das patentes extintas, portanto, em domínio público, podem ser um incentivo ao desenvolvimento de produtos aperfeiçoados; o que mostra um nicho de mercado a ser explorado, no caso de patentes brasileiras.

Consideramos que mesmo com as particularidades de cada país relacionadas às políticas de proteção à propriedade intelectual, existe um sistema internacional de patentes regulamentado pela Organização Mundial da Propriedade Intelectual (OMPI), cujas legislações nacionais precisam ter compartimentos integrados em prol do desenvolvimento do comércio internacional e dos demais eixos das relações internacionais.

Figura 6 - Status legal dos depósitos de patente relacionados ao uso de coco para fabricação de cosméticos

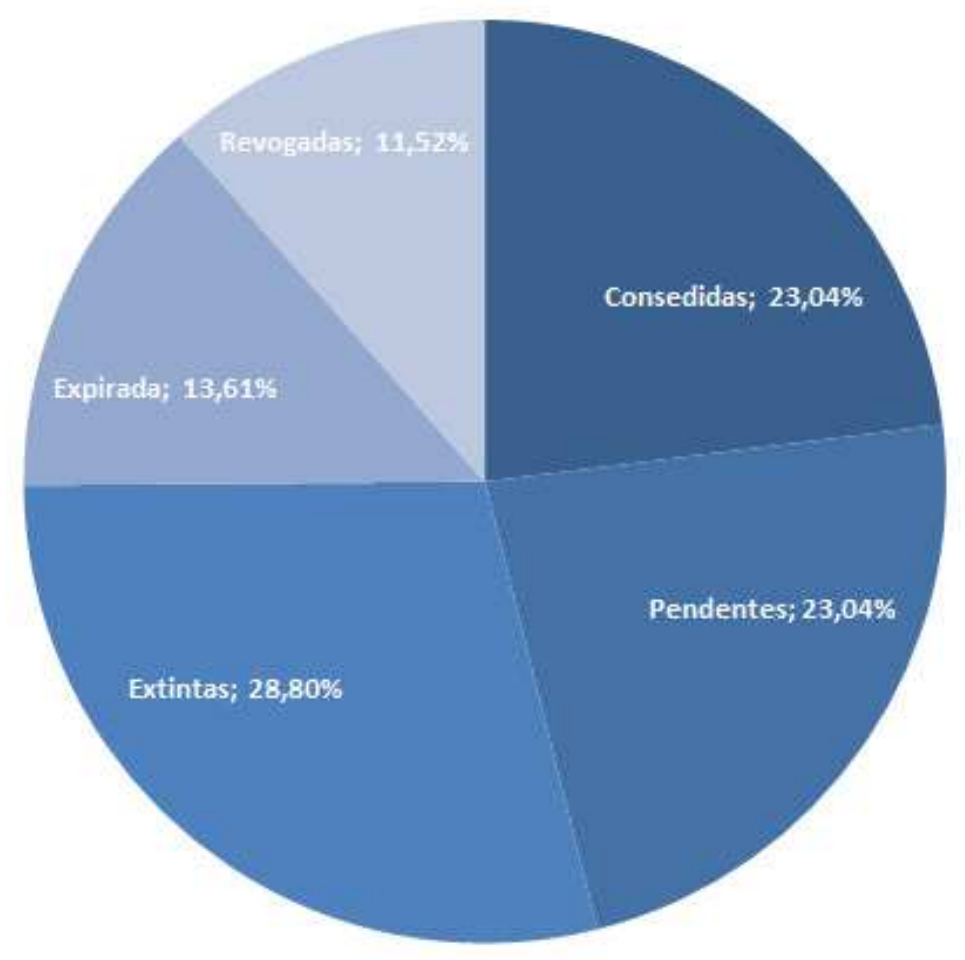

Fonte: Orbit (2018)

Segundo a IPC, os documentos de patentes foram agrupados nas seguintes classes A61K e A61Q, que se referem respectivamente a preparações para finalidades médicas, odontológi- 
cas ou higiênicas e uso específico de cosméticos ou preparações similares para higiene pessoal como podemos observar na Figura 7. Destacando-se as seguintes classes: A61Q 19/00 (21\% dos documentos) preparações para tratamento de pele, A61Q 19/10 (12\%) preparações para limpeza ou banho, A61Q 05/00 (6\%) e A61Q 05/02 (5\%) preparações para limpeza de cabelos, o que mostra a preocupação das empresas no desenvolvimento de produtos voltados para a indústria da beleza.

Para Castro (2010), no decorrer da última década do século XX e nestes primeiros anos do corrente século, todos os setores da economia envolvidos com a produção e/ou manutenção da beleza vêm experimentando significativo crescimento. As observações não deixam dúvidas acerca do impressionante desempenho do setor responsável pela fabricação dos produtos de higiene pessoal, cosméticos e perfumaria, um dos principais filões da indústria da beleza e ainda que posições e movimentos sociais em contrário tenham a pretensão de causar resistência ao avanço da busca pela beleza, ao que parece, esse é um caminho sem volta.

Figura 7 - Percentual de Famílias de Patentes versus Classificação Internacional de Patentes (IPC)

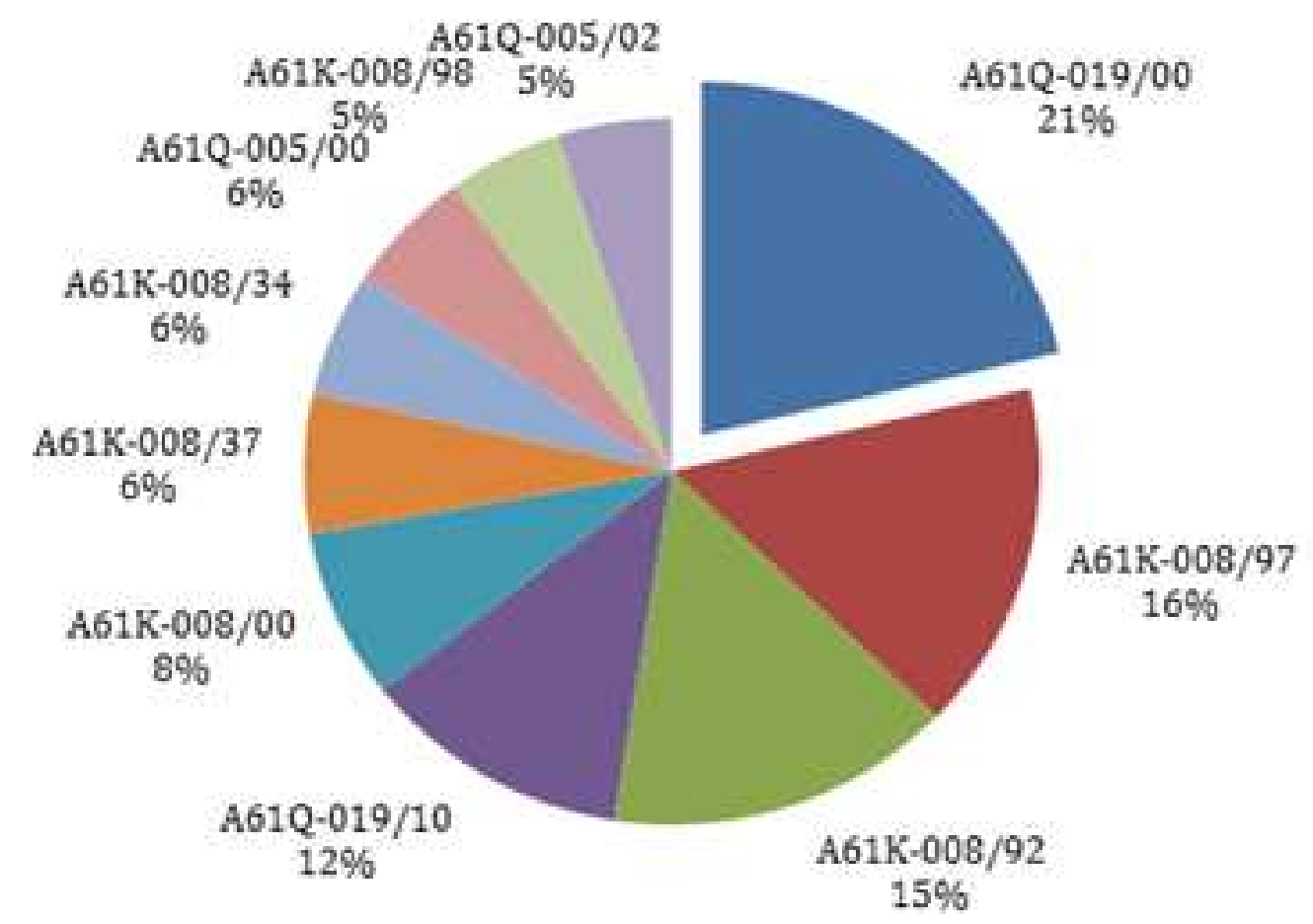

Fonte: Elaborada pelos autores deste artigo, a partir de dados coletados no Orbit (2018)

Considerando os conceitos tecnológicos explorados pelas empresas do setor cosmético, um grande número de tecnologias para diversas aplicações foram destacadas. Formulações destinadas ao clareamento da pele, hidratantes corporais, formulações para tratamento de acne, fragrâncias, protetores solares e cremes anti-idade são alguns exemplos de aplicações tecnológicas desenvolvidas a partir do uso do coco conforme mostrado na Figura 8. 
Figura 8 - Conceitos tecnológicos relacionados a patentes sobre o uso do coco na fabricação de cosméticos

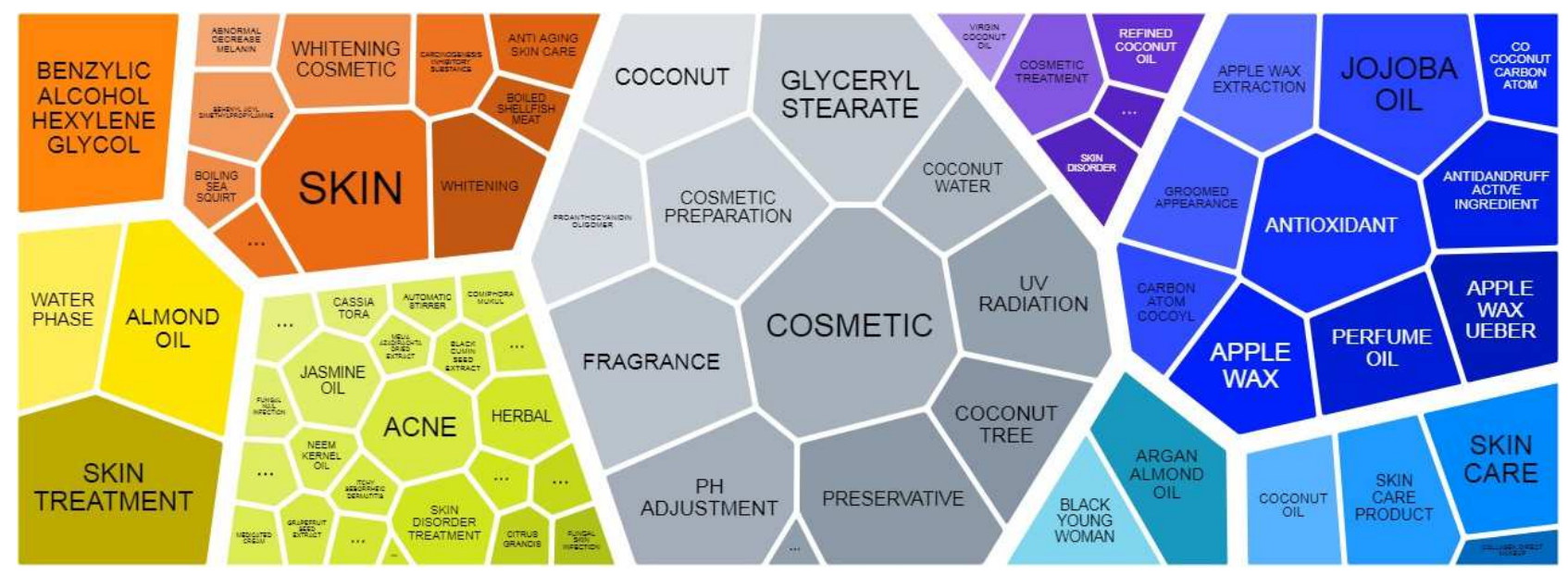

Fonte: Orbit (2018)

O mercado consumidor de produtos cosméticos ecológicos é fortemente impulsionado pela influência dos meios de comunicação e entidades que conscientizam os consumidores acerca de questões ambientais, sociais e ecológicas. De modo geral, o perfil do consumidor dos produtos em questão são pessoas que sabem dos benefícios trazidos pelo consumo de um produto desse tipo e entre os consumidores de cosméticos $41 \%$ já são do sexo masculino e o consumo não está restrito exclusivamente às camadas de maior poder aquisitivo, já que mesmo respondendo pela compra de produtos de menor valor agregado, as classes D e E já significam $28 \%$ dos consumidores do segmento, contra 39\% da classe C e 33\% das classes A e B. Outra perspectiva positiva para o setor nos próximos anos é a de que, além do envelhecimento natural da população, as pessoas também estão começando a usar produtos de beleza cada vez mais cedo.

As inúmeras aplicações apresentadas na Figura 8 mobiliza o setor industrial em diferentes escalas. A indústria extrativista e de processamento, juntamente com cooperativas e associações de produtores rurais de matérias-primas, surgem como os principais agentes da cadeia de cosméticos ecológicos, devido às matérias-primas naturais desempenharem papel-chave no desenvolvimento e sucesso de uma indústria desse segmento. No entanto, cabe ressaltar a participação da indústria química/farmacêutica como necessária na cadeia de mercado por fornecer ingredientes como agentes de consistência, espessantes, antiespumantes, emolientes, emulsionantes, solubilizantes, corantes, dentre outros e ainda a indústria de embalagens, especialmente aquelas que trabalham com embalagens ecológicas.

Esse é um setor promissor e merecedor de maior atenção, especialmente para Brasil, um País dotado de uma das mais diversificadas biodiversidades mundiais e portanto com grande potencial competidor.

\section{Considerações Finais}

Dentro do cenário mundial, no qual a sustentabilidade é a base para o desenvolvimento consciente de uma sociedade, o aproveitamento dos recursos naturais se faz necessário. É nessa perspectiva que este trabalho mostrou que o fruto coco pode ser utilizado para além do uso convencional e igualmente ser largamente difundido. 
Nos 191 documentos de patentes observados sobre o uso do coco para fabricação de cosméticos, a China figurou como o maior depositante - ainda que a proteção das tecnologias tenha sido realizada em grande parte apenas no território chinês - assim como empresas japonesas e sul-coreanas desenvolvem, protegem e difundem seus produtos mundialmente.

A estratégia de busca utilizada permitiu inferir que, apesar de o Brasil ser considerado um grande produtor de coco e ainda detentor de uma área geográfica com condições climáticas favoráveis, o aproveitamento do coco com finalidade industrial está mais voltado para os processos extrativos da água para o consumo e não do fruto para fabricação de cosméticos.

Neste ínterim, podemos citar o trabalho realizado por algumas empresas brasileiras com know-how nessa área que poderia ser mais fortalecido. Podemos citar como exemplo a Natura Cosméticos que inova na política de aproveitamento e valorização da biodiversidade brasileira produzindo cosméticos e gerando valores que estão alinhados a uma visão multidisciplinar para o desenvolvimento de um sistema de produção sustentável levando inovação para o cotidiano das comunidades locais de determinadas regiões brasileiras

Dessa forma, percebemos que existe ainda no Brasil um importante nicho de mercado a ser explorado para o desenvolvimento da indústria da beleza, que envolve, entre outros setores de atividade, cosméticos, cirurgias plásticas, moda, e que vem assumindo posição de destaque na cultura contemporânea. É preciso que haja um maior incentivo à inovação no Brasil para o aproveitamento consciente dos recursos naturais existentes em um país dotado de grande biodiversidade e, portanto candidato a potência no setor biotecnológico.

\section{Referências}

ASSOCIAÇÃO BRASILEIRA DA INDÚSTRIA DE HIGIENE PESSOAL, PERFUMARIA E COSMÉTICOS (ABIHPEC). Panorama do Setor: higiene pessoal, perfumaria e cosméticos. Relatórios (2008 a 2012). São Paulo: ABIHPEC, 2012.

Caderno de Tendências 2014-2015. 2014-2015. Disponível em: <https://abihpec.org.br/ publicacao/caderno-de-tendencias-2014-2015>. Acesso em: ago. 2018.

BRAINER, Simone. Banco do Nordeste. A adaptação do Nordeste ao cenário de modernização da cocoicultura brasileira. Caderno Setorial Escritório Técnico de Estudos Econômicos do Nordeste - ETENE, [S.1.], ano 2, n. 18, out. 2017. Disponível em: <https://www.bnb.gov.br/ documents/80223/2666752/18_coco_V4.pdf/93f42437-8108-ebc6-0f78-0cd8f41957b0>. Acesso em: jun. 2018.

BRASIL. Lei $\mathbf{n}^{\circ}$ 9.279, de 14 de maio de 1996. Dispõe sobre regulação de direitos e obrigações relativos à Propriedade Industrial. Brasília, DF, 14 de maio de 1996. Disponível em: <http://www. agricultura.gov.br/assuntos/sustentabilidade/tecnologia-agropecuaria/arquivos-de-legislacoes-detecnologias/lei-no-9-279-de-14-de-maio-de-1996.pdf/view > . Acesso em: jun. 2018.

CASTRO, A. L. Indústria da beleza: uma abordagem sócio-antropológica do culto ao corpo na cultura contemporânea. Latitude, Alagoas, v. 4, n. 1, p. 54-73, 2010.

COSTA, H. K. S.; LIMA, L. C. P. Fibra de Coco: estudo exploratório sobre registro de patentes.

Cadernos de Prospecção, Salvador, v. 11, Edição Especial, p. 387-398, abr./jun. 2018.

INSTITUTO DE PESQUISA ECONÔMICA APLICADA (IPEA). Texto para discussão 2130: 
ambiente de negócios, investimentos e produtividade. Rio de Janeiro: IPEA, 2015.

LASZLO, Fabian. A importância do óleo de coco, ácido láurico. 2017. Disponível em: < http:// www.toqueativo.com.br/index.php?option $=$ com_content\&view $=$ article\&id $=225 \&$ Itemid $=135>$ Acesso em: jun. 2018.

MARTINS, C. R.; JESUS JR., L. A. Evolução da produção de coco no Brasil e o comércio internacional. Aracaju: Embrapa Tabuleiros Costeiros, 2011. Documentos 164. Disponível em: $<$ http://www.cpatc.embrapa.br/publicacoes_2011/doc_164.pdf>. Acesso em: jun. 2018.

NEVES, K. Nanotecnologia em cosméticos. Cosmetics \& Toiletries, EUA, v. 20, jan./fev., p. 22, 2008.

ORBIT INTELLIGENCE. Disponível em: <https://www32.orbit.com/>. Acesso em: jun. 2018.

ORGANIZAÇÃO MUNDIAL DA PROPRIEDADE INTELECTUAL (OMPI). Relatório de Indicadores Mundiais de Propriedade Intelectual (2017). 2017. Disponível em: < http://www. wipo.int/edocs/pubdocs/en/wipo_pub_941_2017.pdf>. Acesso em: jun. 2018.

PATENTS ONLINE. Disponível em: <http://www.freepatentsonline.com>. Acesso em: jun. 2018.

PERIÓDICOS CAPES. Disponível em: <http://www.periodicos.capes.gov.br/> . Acesso em: jun. 2018.

FARMACEUTICAS. O óleo de coco e suas propriedades. 2018. Disponível em: <http://www. farmaceuticas.com.br/oleo-de-coco-e-suas-propriedades>. Acesso em: jun. 2018.

REVISTA COSMETIC INNOVATION. 2018. Crescimento dos cosméticos naturais, orgânicos, veganos e éticos é tendência irreversível. Disponível em: <http://www.cosmeticinnovation.com. $\mathrm{br} / \mathrm{crescimento-dos-cosmeticos-naturais-organicos-veganos-e-eticos-e-tendencia-irreversivel}>$. Acesso em: jun. 2018.

REVISTA VEJA. Brasil perde posição no consumo de cosmético, mas setor avança. 2018.

Disponível em: <https://veja.abril.com.br/economia/brasil-perde-posicao-no-consumo-de-cosmeticomas-setor-avanca/>. Acesso em: jun. 2018.

SERVIÇO BRASILEIRO DE APOIO ÀS MICRO E PEQUENAS EMPRESAS (SEBRAE). Potenciais negócios do coco verde. 2018. Disponível em: <http://www.sebraemercados.com.br/potenciaisnegocios-do-coco-verde>. Acesso em: jun. 2018.

O cultivo e o mercado do coco. Disponível em: http://www.sebrae.com.br/sites/

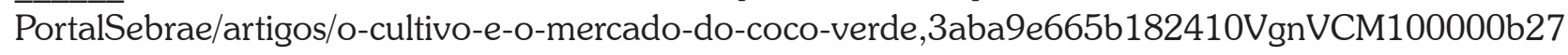
2010aRCRD. Acesso em: 22 jun. 2018.

\section{Crescimento dos cosméticos naturais orgânicos veganos e éticos e tendência}

irreversível. Disponível em: < https://www.cosmeticinnovation.com.br/crescimento-dos-cosmeticosnaturais-organicos-veganos-eeticos-e-tendencia-irreversivel/> . Acesso em: 24 jun. 2018.

TOMMASI, A. C. et al. Prospecção tecnológica sobre a utilização de óleo de coco para produção de biodiesel. Cadernos de Prospecção, Salvador, v. 7, n. 1, p. 107-116, jan./mar. 2014. 


\section{Sobre os Autores}

\section{Isabella Sampaio}

E-mail: isabellassampaio@gmail.com Mestranda do Programa de Pós-Graduação em Propriedade Intelectual e Transferência de Tecnologia para a Inovação (PROFNIT) da Universidade Federal da Bahia (UFBA); bacharel em Relações Internacionais, pela Faculdades Integradas da Bahia (FIB); e em Administração, pela UNIFACS.

Endereço profissional: Agência UNEB de Inovação Parque Tecnológico da Bahia Edf. Tecnocentro - R. Mundo, 121 - Trobogy - Salvador, BA. 41745-715

\section{Solange Ferreira}

E-mail: solangeferreirar@gmail.com

Mestranda do Programa de Pós-Graduação em Propriedade Intelectual e Transferência de Tecnologia para Inovação (PROFNIT) da Universidade Federal da Bahia (UFBA); pós-graduada em MBA - Executivo em Marketing Estratégico, pela Faculdade de Ciências Gerencias da Bahia/Centro Interamericano de Desenvolvimento (CENID/ Business School); e graduada em Economia, pela Faculdade Católica de Ciências Econômicas da Bahia.

Endereço profissional: Conselho Regional de Educação Física da 13a Região- CREF13/BA. Rua Arthur de Azevedo Machado, 289, Es Marlim Azul - Térreo - Costa Azul, Salvador, BA.

\section{Paulo Juiz}

E-mail: paulojuiz@gmail.com

Pós-doutor em Farmácia, pela Universidade Federal da Bahia (UFBA); doutor em Biotecnologia (UEFS/FIOCR UZ-BA), em doutorado sanduíche, pela Università Degli Studi di Ferrara - Itália; mestre em Imunologia, pela UFBA; especialista em Biologia Molecular Aplicada à Medicina Forense (UNEB); e especialista em Microbiologia, pela UFBA.

Endereço profissional: Universidade Federal do Recôncavo da Bahia Rua Rui Barbosa, 710, Centro - Cruz das Almas, BA. CEP: 44380-000. 